\title{
Reproductive Characteristics of Abyssinian Jennies Exposed to Stallions and Jackasses
}

Getachew Tadesse ${ }^{1^{*}}$ and Melaku Tefera ${ }^{2}$

${ }^{1}$ Department of biomedical Sciences, School of veterinary medicine, College of Health

Sciences, Addis Ababa University, P.O.Box 34, Debrezeit, Ethiopia

${ }^{2}$ College of veterinary Medicine, Haramaya University, P.O. Box 144, Haramaya, Ethiopia

* Corresponding author:

\section{Abstract}

The aim of the study was to describe the intraspecies and interspecies sexual interactions and reproductive features Abyssinian type jennies exposed to jackasses and stallions. Twenty post-pubertal jennies, 3 jackasses and 4 stallions were used in the study. Jennies were divided in to two groups of ten each (stallion group and jack group). $\mathrm{PGF}_{2 \alpha}$ was used to induce heat. A vasectomized jackass was used to assist heat detection. Jennies in the jack group were bred by two jackasses and jennies in the stallion group were bred by a stallion. Mating was on the $6^{\text {th }}$ and $8^{\text {th }}$ days after $\mathrm{PGF}_{2 \alpha}$ injection and within the last three days after spontaneous return to heat. The durations of estrus and the estrus cycle were $7.4 \pm 0.9$ (mean \pm SD) and $24.3 \pm 2.1$ (mean $\pm \mathrm{SD}$ ) days respectively. All jennies were receptive to jackasses but not to stallions. The number of cycles per pregnancy in the intraspecies mating was lower than the number of cycles in the interspecies mating $(\mathrm{p}<0.05)$. The lengths of gestation of jennies in foal with jackasses and a stallion were $370.2 \pm 4.5$ (mean $\pm \mathrm{SD}$ ) and 330 days respectively. The mating resulted in five donkey foals and a hinny. The study showed that Abyssinian jennies have a high intraspecies reproductive potential but low pregnancy rate and abortion appear limitations in interspecies hybridization.

Key words: Hinny, Jackass, Jenny, Reproduction, Stallion

http://dx.doi.org/10.4314/evj.v17i2.6 


\section{Introduction}

Equines have a prominent position in the agricultural and transport sectors of the rural and several urban setups of Ethiopia. The donkey, horse and mule populations are estimated at 5.4, 1.8 and 0.4 million respectively (CSA, 2008).

Studies on the interspecies reproductive characteristics of domestic equids are limited. Mules are commonly produced in several countries (Allen and Short, 1997). Although the comparative conception rates are not recorded, the fertility of the mating to produce hinnies is lower than the mating to produce mules (Allen et al., 1993).

Abyssinian donkeys breed throughout the year with the short rainy months as their major mating and foaling months (Melaku Tefera, 2004; Alemayehu Lemma, 2004). Despite mule production is a common practice in the highlands Ethiopia there are no recorded attempts to produce hinnies. The objectives of this study were to describe the intraspecies and interspecies sexual interactions and reproductive features of Abyssinian type jennies exposed to jackasses and stallions under controlled breeding conditions.

\section{Materials and Methods}

Animals and management

Twenty apparently healthy jennies, 3 jackasses and 4 stallions were used in the study. All jennies were post pubertal of which four were maidens and 16 were parous. Jennies were randomly divided in to two groups of ten animals each (stallion group and jack group) and identified by ear notches. All animals were vaccinated against Anthrax and Tetanus and dewormed. Jennies grazed during the day and supplemented with a mixture of wheat bran and Noug cake (Guizoitia abyssinica). The breeder jackasses were rationed by the cattle fattening farm of the Faculty of Veterinary Medicine, Addis Ababa University. A stallion used to breed jennies was fed with hay and supplemented with a mixture of barley, wheat bran and Noug cake.

Heat induction and Mating

Heat was induced by $\mathrm{PGF}_{2 \alpha}$ (dinoprost tromethamine, LUTALYSE ${ }^{\circledR}, 5 \mathrm{mg} / \mathrm{ml}$ sterile solution) at a dose rate of $22 \mu \mathrm{g} / \mathrm{Kg}$ body weight $(1 \mathrm{mg} / 45.5 \mathrm{Kg}$ body weight). Each jenny received $0.6 \mathrm{ml} \mathrm{PGF}_{2 \alpha}$ by an intramuscular injection at the neck muscle. A vasectomized jackass was used to assist heat detection. 


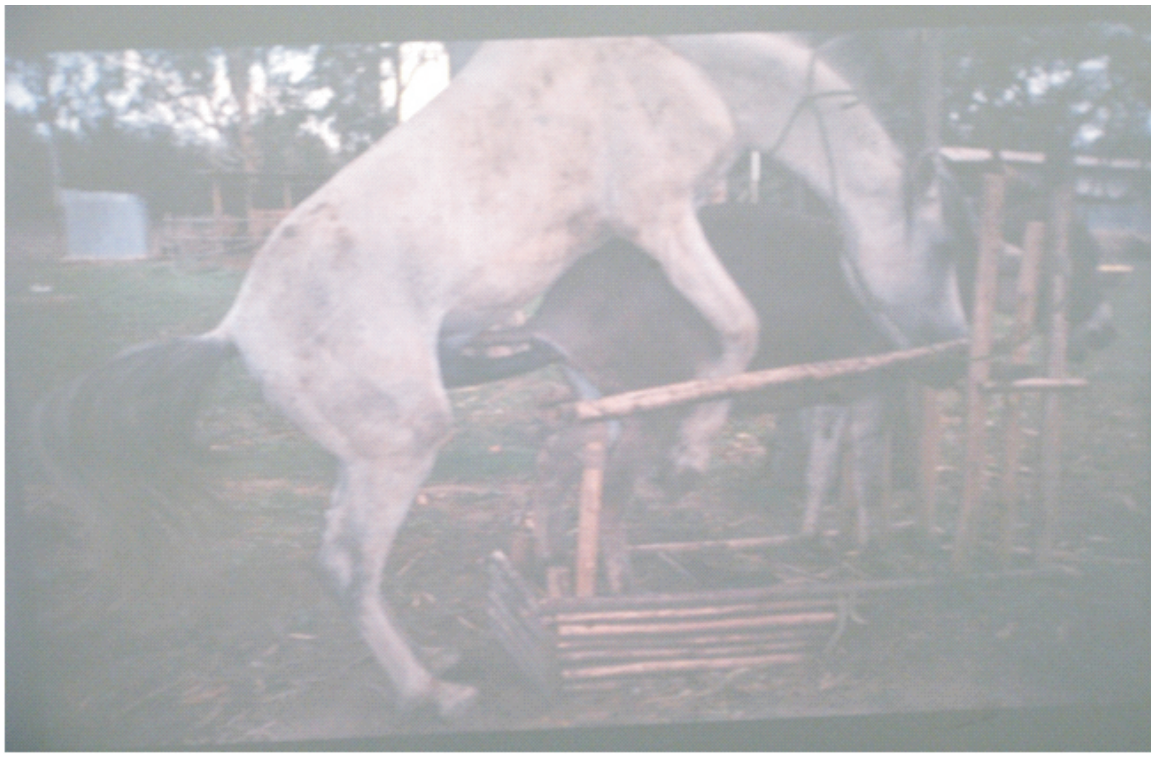

Figure 1. A stallion mating with a jenny.

A jenny was considered sexually receptive if it champed and displayed the associated postures (backing of the ears, extension of the neck and immobility) when approached by a jackass or a stallion. A mare was used to evaluate the natural intraspecies sexual desires of the stallions. The flehmen reaction, erection of the penis, mounting, thrusting and copulation were used as indicators of the sexual desires of jackasses and stallions to jennies in heat. Jennies in the jack group were bred by two jackasses and mating was without any assistance. Of the four stallions, one was strongly attracted and mated with jennies in a mating crate (Fig. 1). The mating was on the $6^{\text {th }}$ and $8^{\text {th }}$ days after $\mathrm{PGF}_{2 \alpha}$ injection and within the last three days after spontaneous return to heat. Pregnancy was determined by non return to heat and by palpation per rectum 60-90 days after service. The length of gestation was calculated from the first mating date and the date of foaling.

Data analysis

Descriptive statistics was used to summarize data. The Fisher's exact test was used to test associations. Alpha was set at 0.05 . The data was analysed by Epi Info ${ }^{\circledR}$ (Version 3.5.1., Centre for Disease control, USA). 


\section{Results}

Sexual behaviors

Jennies were in heat $3.6 \pm 1.6$ days (mean \pm SD) post prostaglandin administration. Jawing and the associated postures were the pre coital and coital sexual displays of jennies to jackasses. All jennies were receptive to jackasses but not to stallions. The durations of estrus and the estrus cycle were $7.4 \pm 0.9$ (mean \pm SD) and $24.3 \pm$ 2.1 (mean $\pm \mathrm{SD}$ ) days respectively (Table 1).

Table 1. Durations of estrus and the estrus cycle of Abyssinian type jennies.

\begin{tabular}{lll}
\hline Mating groups & $\begin{array}{l}\text { Estrus days } \\
(\text { mean } \pm \mathrm{SD})\end{array}$ & $\begin{array}{l}\text { Estrus cycle days } \\
(\text { mean } \pm \mathrm{SD})\end{array}$ \\
\hline Jennies with Jacks $(\mathrm{n}=9)$ & $7.8 \pm 0.5$ & $25.3 \pm 2.7$ \\
Jennies with Stallions $(\mathrm{n}=9)$ & $7.0 \pm 0.5$ & $23.4 \pm 2.1$ \\
Over all $(\mathrm{n}=18)$ & $7.4 \pm 0.9$ & $24.3 \pm 2.4$ \\
\hline
\end{tabular}

\section{Pregnancy}

Table 2 presents the gestation features of jennies mated with jackasses and stallions. The number of pregnant jennies in the interspecies mating was lower than the number of pregnant jennies in the intraspecies mating $(\mathrm{p}<0.05)$. The number of cycles per pregnancy was lower in the intraspecies mating than in the interspecies mating $(\mathrm{P}<0.05)$. Abortion occurred at 192 to 254 days of gestation in the jack group and at 147 and 159 days in the stallion group. The length of gestation of jennies in foal with jackasses was $370.2 \pm 4.5$ (mean $\pm \mathrm{SD}$ ) days and ranged from 361 to 388 days. 
Table 2. Gestation characteristics of jennies by mating groups.

\begin{tabular}{llllll}
\hline Mating groups & Pregnant & NC & NCP & Aborted & Foaled \\
\hline Jennies with Jacks $(\mathrm{n}=10)^{\mathrm{a}}$ & $9^{\mathrm{b}}$ & 27 & 3 & 3 & 5 \\
Jennies with Stallions $(\mathrm{n}=10)^{\mathrm{c}}$ & 3 & 47 & 15.7 & 2 & 1 \\
Overall $(\mathrm{n}=18)$ & 12 & 74 & 6.5 & 5 & 6 \\
\hline
\end{tabular}

$\mathrm{NC}=$ Numbers of cycles

NCP $=$ Numbers of cycles per pregnancy

$\mathrm{a}=$ One jenny was metritic and did not respond to $\mathrm{PGF}_{2 \alpha}$ and was not bred.

$\mathrm{b}=\mathrm{A}$ pregnant jenny died of an unknown reason.

$\mathrm{c}=$ One jenny was pregnant before the start of the experiment and did not respond to $\mathrm{PGF}_{2 \alpha}$.

The length of gestation of the jenny in foal with the stallion was 330 days. Foaling didn't require assistance in both groups and was higher in jennies bred by jackasses compared to jennies bred by the stallion $(\mathrm{p}<0.05)$. The mating resulted in five donkey foals and a hinny (Fig. 2). The birth weight of donkey foals and the hinny were $13.3 \pm 1.0 \mathrm{Kg}($ mean $\pm \mathrm{SD})$ and $16 \mathrm{Kg}$ respectively.

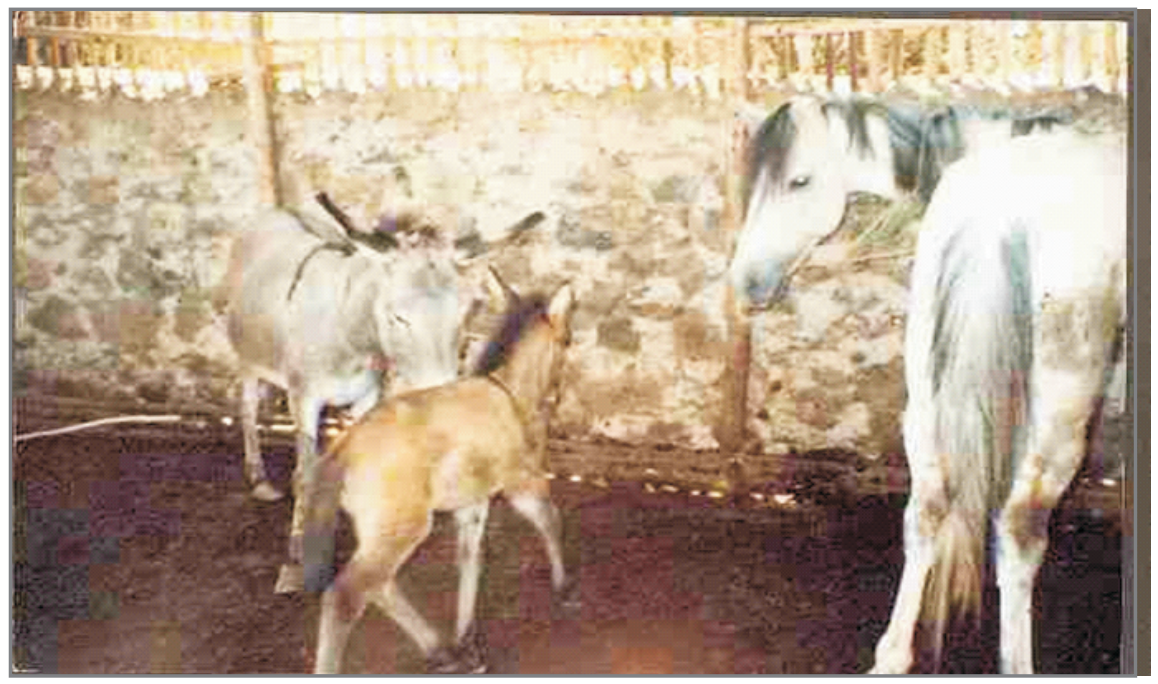

Figure 1. A hinny with its dam and sire. 
The growth rate of donkey foals and the hinny during the first 8 weeks of life were $0.275 \pm 0.06 \mathrm{Kg}$ (mean $\pm \mathrm{SD})$ and $0.375 \mathrm{Kg}$ respectively.

\section{Discussion}

The sexual behavior of Abyssinian type jennies is similar with other donkey breeds. The onset of estrus after treatment with $\mathrm{PGF}_{2 \alpha}$ was comparable with reports for Martina Franca jennies (Carluc cio et al., 2009) and mammoth asses (Blanchard et al., 1999) and the durations of estrus and the estrus cycle were in accord with reports for other donkey breeds (Henry et al., 1987; Taberner et al., 2008).

Jennies were receptive to jackasses but not to stallions. The pre coital and coital intraspecies sexual displays were in agreement with other reports (Henry et al., 1991; Henry et al., 1998; McDonnell, 1998). Although jawing is a unique sign of sexual receptivity of jennies in heat (McDonnell, 1998), unreceptive jennies were also observed jawing when mounted by jackasses and stallions. The pre coital sexual displays of jennies to jackasses but their apparent disregard to stallions could be due to intraspecies mate preferences. Rearing together and cohabitation were reported to be important factors in interspecies equine sexual interactions and hybridizations (Bekele Megersa et al., 2006; Canisso et al., 2009).

The number of pregnant jennies in the interspecies mating was lower than the number of pregnant jennies in the contemporary intraspecies mating. The result is comparable with a previous report by Allen and Short (1997) where an interspecies pregnancy rate of $14 \%$ was recorded in 159 mated / inseminated estrus cycles of which 11 were from the same three donkeys bred in successive years. Marked decreases in major histocompatibility (MHC) restricted CTL activities were reported in both mares and jennies that carried intraspecies pregnancies but not in mares with mule conceptuses and failure to down-regulate cellular immune responses was suggested as a subtle barrier in interspecies reproductive successes (Baker et al., 1999).

Abortion was one of the causes of lower foaling frequencies in both the intraspecies and interspecies mating. Several environmental pathogens and equine specific infectious agents were implicated as causes of significant embryonic and fetal death losses in mares (Smith et al., 2003).

The gestation length of jennies that carried donkey foals is in agreement with other donkeys (Fielding, 1988; McDonnell, 1998). However, the gestation length of the jenny that carried a hinny was shorter by about a month as compared to that of the contemporary jennies in foal to jackasses. The shorter gestation length the jenny 
This study showed that if kept under good management conditions, Abyssinian jennies have a high intraspecies reproductive potential. Poor courtship behavior, low pregnancy rate and abortion may be the major factors that limit the interspecies hybridization. Further studies are required to describe the conception rates and causes of abortions.

\section{Acknowledgements}

This study was funded by the Research Program on Sustainable Use of Dry land Biodiversity (RPSUD). We would like to thank the Institute of Biodiversity and the Faculty of Science, and the Faculty of Veterinary Medicine, AAU, for processing the grant application. We also would like to thank Dr. Gemechu Wirtu, Dr. Takele Abayneh, Dr. Roman Tiruneh Dr. Azage Tegene and Dr. Endris Hansar for their help in the study.

\section{References}

Allen, W.R., and Short, R.V., 1997. Interspecific and Extra specific Pregnancies in Equids: Anything Goes. J. Hered., 88(5), 384-392.

Allen, W.R., Kydd, J.H., and Antczak, D.F., 1993. Interspecies and extra species equine pregnancies. In: McKinnon, A.O., and Voss, J.L. (Eds). Equine reproduction. Lea and Febiger, Philadelphia, pp. 536-553.

Baker, J.M., Bamford, A.I., and Antczak, D.F., 1999. Modulation of allospecific CTL responses during pregnancy in equids: an immunological barrier to interspecies matings? $J$. Immunol., 162, 4496-4501.

Blanchard, T.L., Taylor T.S., and Love, C.L., 1999. Estrous cycle characteristics and response to estrus synchronization in mammoth asses (Equus asinus americanus). Theriogenology, $52,827-834$.

Canisso, I.F., Coutinho da Silva, M.A., Morel, M.C.G., and McDonnell, S., 2009. How to Manage Jacks to Breed Mares. AAEP., 342-348.

Carluccio, A., Tosi, U., Contri, A., De Amicis, I., and Veronesi, M.C., 2006. Corpus Luteum sensitivity to PGF2 $\alpha$ administration in the Martina Franca Jenny. Vet. Res. Commun. (Suppl.), 30(1), 171-173.

CSA, 2008. Agricultural sample survey reports on livestock and livestock characteristics, private and peasant holdings, Statistical Bulletin. Central Statistics Authority of Ethiopia (CSA),. Addis Ababa, Ethiopia. 
Fielding, D., 1988. Reproductive characteristics of the jenny donkey-Equus asinus: a review. Trop. Anim. Hlth. Prod., 20, 161-166.

Henry, M., Figueiredo, A.Z.F., Palhares, M.S. and Coryn, M., 1987. Clinical and endocrine aspects of the oestrous cycle in donkeys (Equus asinus). J. Reprod. Fertil. (Suppl.), 35, 297-303.

Henry, M., Lodi, L.D., and Gastal, M.M.F.O., 1998. Sexual behavior of domesticated donkeys (Equus asinus) breeding under controlled or free range management systems. Appl. Anim. Behav. Sci., 60, 263-276.

Henry, M., McDonnell, S.M., Lodi, L.D., and Gastal E.L., 1991. Pasture mating behavior of donkeys (Equus asinus) at natural and induced estrus. J. Reprod. Fertil., 44, 77-86.

Lemma A., 2004. Case studies on reproductive activity of equines in relation to environmental factors in central Ethiopia. PhD Thesis, Humboldt University, Berlin.

McDonnell, S.M., 1998. Reproductive behavior of donkeys (Equus asinus). Appl. Anim. Behav. Sci., 60, 277-282.

Megersa, B., Biffa, D., and Kumsa, B., 2006. A mysterious Zebra-Donkey hybrid (Zedonk or Zonkey) produced under natural mating: a case report from Borana, southern Ethiopia. Anim. Prod. Res. Adv., 2(3), 148-154.

Smith, K.C., Blunden, A.S., Whitwell, K.E., Dunn, K.A., and Wales, A.D., 2003. A survey of equine abortion, stillbirth and neonatal death in the UK from 1988 to 1997. Equine Vet. J.235(5), 496-501.

Taberner, E., Medrano, E., Pen Rigau, T., Miro, J., 2008. Estrus cycle characteristics and prediction of ovulation in Catalonian Jennies. Theriogenology, 70, 1489-1497.

Tefera, M., 2004. Phenotypic and reproductive characteristics of donkeys in Ethiopia. In: Proceedings of the fourth international colloquium on working equines, 20-26 April, 2002,Hama,Syria. 